\title{
Zonation on sandy tropical beaches: a case study using Dotilla intermedia (Brachyura: Ocypodidae)
}

\author{
Christopher J. Allen ${ }^{1,2, *}$, Gordon L. J. Paterson ${ }^{2}$, Lawrence E. Hawkins ${ }^{1}$, \\ Chris Hauton $^{1}$, Paul F. Clark ${ }^{2}$, Chittima Aryuthaka ${ }^{3}$
}

\author{
${ }^{1}$ School of Ocean and Earth Science, University of Southampton, National Oceanography Centre, Southampton SO14 3ZH, UK \\ ${ }^{2}$ Department of Zoology, The Natural History Museum, London SW7 5BD, UK \\ ${ }^{3}$ Department of Marine Science, Kasetsart University, Band Khen, Bangkok 10900, Thailand
}

\begin{abstract}
The factors underlying intertidal zonation patterns of fauna on exposed sandy beaches were investigated and focussed on the crab Dotilla intermedia. Dotillids form dense populations on sandy beaches across the Indo-Pacific region and play an important role in processing superficial sediment. Analyses from 2 study sites indicate that the gradient of the beach slope was correlated to the height from the high water mark at which the boundaries of the crab zones occurred, with physical factors associated with the beach gradient influencing the distribution of $D$. intermedia on the beach. The upper limit of the dotillid zone was controlled by the total water content of the sediment, with $D$. intermedia absent in areas with total water content less than $15 \%$. Tidal influences defined the lower boundary of the dotillid zone, with crabs requiring an area with a minimum exposure time between tidal immersions ( 4 to $5 \mathrm{~h}$ ) to feed on the sediment. Within the dotillid zone, the mid and low shore regions were the most densely populated. There were differences in the distribution of $D$. intermedia according to crab size, with the low shore area dominated by small crabs, and larger crabs occurring higher up the beach. In terms of the time constraints between successive tidal immersions, the high shore was a more preferential area for large crabs to live in, giving them greater time to feed, construct burrows and engage in other activities, leaving low shore areas open for the settlement of juveniles.
\end{abstract}

KEY WORDS: Zonation $\cdot$ Dotilla intermedia $\cdot$ Sandy beach ecology $\cdot$ Autoecology

Resale or republication not permitted without written consent of the publisher

\section{INTRODUCTION}

Exposed sandy beaches are amongst the harshest aquatic ecosystems on Earth (McLachlan et al. 1993). In these physically controlled environments biological interactions are minimal and communities are structured by the independent responses of individual species to the physical environment, as suggested by the autoecological hypothesis (Noy-Meir 1979, McLachlan 1990). Experimental studies have shown an increase in community level descriptors from harsh to more benign beaches (e.g. McLachlan et al. 1981, 1993, Jaramillo et al. 1995), matching the predictions of this hypothesis. The review by McLachlan \& Dorvlo (2005) indicates that the most recent studies of sandy beach ecology have correlated the physical shore attributes with biotic community level indices, such as species diversity, total abundance and biomass. However, these biotic measures reflect the summation of the responses of individual populations. The investigation of the relationship between the distribution of key species and their physical environment can provide an insight into the processes that structure community level patterns. The present study departs from the usual community level approach to beach ecology by investigating the autoecology of a key macrofaunal species of a tropical sandy shore.

The present study examines the autoecological zonation of a littoral crab species, Dotilla intermedia De Man 1888, on 2 exposed intermediate beaches from 
the Laem Son National Park in Ranong Province, Thailand. Crabs of the genus Dotilla are ecologically important members of tropical sandy shore intertidal communities. Dotillid crabs are found on tropical shores and mudflats from East Africa and the Red Sea eastwards to Japan (Alcock 1900). They live at high densities on beaches, with reports of numbers reaching over 500 individuals $\mathrm{m}^{-2}$ (Hartnoll 1973, Hails \& Yaziz 1982). Dotilla spp. construct simple burrows in which they remain whilst submerged by the tide. The burrow acts as an important refuge from predators and environmental exposure such as heat irradiation and desiccation (Warner 1977). After the tide has receded the crabs emerge to feed on organic detritus from the surface layer of the sediment (Tweedie 1950). Crabs feed in a radial pattern centred on the burrow, always leaving a path clear of feeding pellets to allow retreat back into their burrow (Luschi et al. 1997). The burrowing and feeding activities of the crabs at low tide result in the rapid turnover of the sediment (Fishelson 1983, Bradshaw \& Scoffin 1999), which has a significant effect on the meiofaunal community by preventing colonisation of species not adapted to intense surface disturbance and lowering numbers of harpacticoid copepods (Olafsson \& Ndaro 1997). Whilst several dotillid species, such as Dotilla myctiroides (e.g. Tweedie 1950, Hails \& Yaziz 1982, Takeda et al. 1996, Bradshaw \& Scoffin 1999) and D. fenestrata (e.g. MacNae \& Kalk 1962, Hartnoll 1973, Gherardi et al. 1999), have been extensively examined, there have been very few studies on $D$. intermedia.

In this study, we investigated which physical factors control the boundaries of the zone inhabited by Dotilla intermedia. We examined the relationship between the beach gradient and the extent and position of the dotillid zone and looked at which physical factors associated with the beach gradient may be responsible for the observed patterns. We also examined whether there was any evidence of size segregation within the dotillid zone and whether this in turn is related to available foraging time (which is governed by tidal immersion and exposure), population density or sediment particle size and organic content.

\section{MATERIALS AND METHODS}

Study area. Two exposed oceanic intermediate sandy beaches in the Laem Son National Park, Ranong Province, Thailand, were examined: Prapas Beach $\left(9^{\circ} 21^{\prime} 57 \mathrm{~N}, 98^{\circ} 23^{\prime} 41 \mathrm{E}\right)$ and Bang Ben (9³6' $11 \mathrm{~N}$, $98^{\circ} 27^{\prime} 56$ E). Both beaches consist of moderately sorted fine sand, with Prapas Beach possessing a steeper slope than Bang Ben (3.69 and 2.26\%, respectively). The macrofaunal assemblages on these beaches were characterised by the presence of the crabs Scopimera sp. and Ocypode sp. in addition to Dotilla intermedia, together with the tubes of the polychaete Diopatra sp. On each beach, the dotillid zone runs from approximately the mean high water neap to the mean low water neap, with a zone of Scopimera sp. occurring higher on the shore.

Data collection and analysis. Transects were used to construct beach profiles and delimit species boundaries. Transects were established perpendicular to the shoreline, running from the extreme high water spring (EHWS) mark to low water. Starting at EHWS, the vertical drop in height $(\mathrm{cm})$ was measured every metre. The heights at which the boundaries of the Scopimera sp. zone and the dotillid zone occurred were recorded for each transect. Transects were spaced $200 \mathrm{~m}$ apart to capture changes in topology and heterogeneity across the beach. To ensure the same level of exposure, all transects on a beach were measured at low water during a single spring tide. Five transects were measured on Prapas Beach in November 2007 and were repeated in April 2008. Only 3 transects were measured on Bang Ben in April 2008, as fewer transects could be completed over one tidal cycle on the wider beach. The sampling periods were timed to avoid the monsoon season. Dotillid crabs retreat down their burrows during rainfall, which also acts to destroy their feeding pellets, thus leaving no trace as to which area on the beach the crabs occupy.

Quadrats $\left(0.25 \mathrm{~m}^{2}\right)$ were placed at approximately $2 \mathrm{~m}$ intervals across the dotillid zone on each transect. The numbers of crabs present in each quadrat were counted and the quadrat was photographed with a Canon EOS 400D digital SLR camera. These photographs were then analysed using MapInfo Professional v. 9. For each burrow in a quadrat, the burrow diameter and the area in which each resident crab fed were measured, along with the distance to the next nearest burrow.

Ocypodidae crab carapace width (CW) is closely related to burrow diameter (BD) (Zwarts 1985, Dray \& Paula 1998, Lee \& Lim 2004), with the exact relationship varying amongst species. A preliminary study was conducted to establish the relationship between CW and BD for Dotilla intermedia. The diameters of 30 burrows, covering a range of sizes, were measured to the nearest $0.01 \mathrm{~mm}$ with a pair of digital vernier calipers, along with the $\mathrm{CW}$ of the resident crab. BD was regressed against CW. There was a highly significant linear relationship between crab $\mathrm{CW}$ and $\mathrm{BD}\left(\mathrm{r}^{2}=\right.$ 0.934, $\mathrm{p}<0.0001$ ); therefore, BD was used as a proxy for CW in analysing body size (Fig. 1).

The dotillid zone on each beach (Prapas in 2007 and 2008 and Bang Ben in 2008) was split into 3 equal areas (upper, middle and low) and crab size frequency distributions were constructed from the quadrat data from 


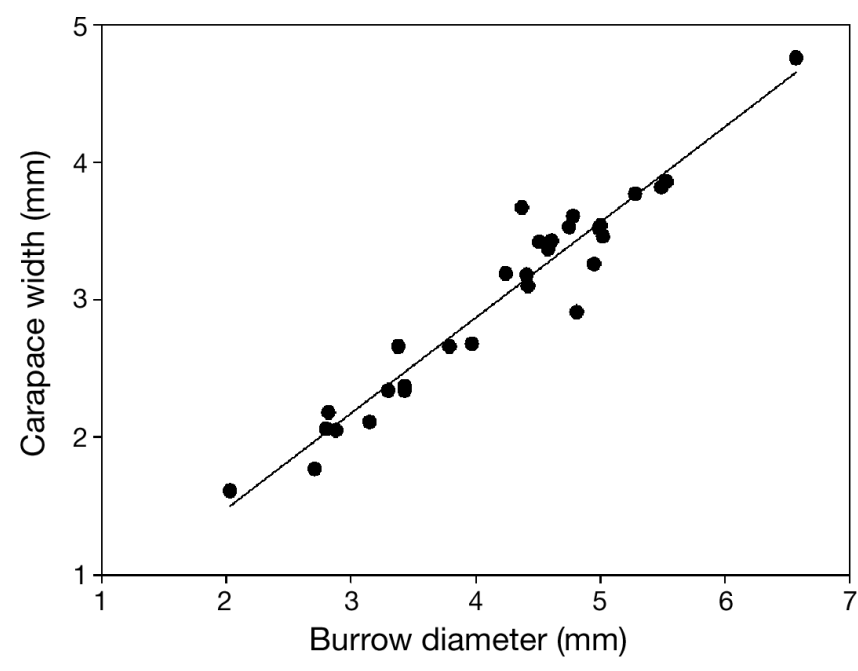

Fig. 1. Dotilla intermedia. Linear regression of burrow diameter $(\mathrm{mm})$ plotted against resident crab carapace width $(\mathrm{mm})$. Carapace width $=0.6952 \times$ burrow diameter $+0.0878, \mathrm{r}^{2}=$ $0.934, \mathrm{n}=30$

each area. Kolmogorov-Smirnov tests (Sokal \& Rohlf 1995) were used to compare the size frequency distribution between each of the areas on each beach and to compare distributions of each area with its respective area on the other beaches.

Mean crab CW and the mean feeding area within each quadrat were log transformed and correlated using Pearson's correlation coefficient. The nearest neighbour distances were used to analyse the spatial patterns within each quadrat using an established method (Clark \& Evans 1954), generating an R-value for each quadrat. The R-value takes a range between 0 and 2.1, and describes the spatial pattern within an area. An R-value of 0 indicates an aggregated distribution, whilst an R-value of 1 shows a random distribution, and a value of 2.1 demonstrates a regular distribution. The R-value was compared with the density within each quadrat.

Sediment samples were collected in April 2008 from both Prapas Beach and Bang Ben. Cores of $5 \mathrm{~cm}$ diameter were taken to a depth of $10 \mathrm{~cm}$ at 5 points along each transect: above the dotillid zone $(1 \mathrm{~m}$ above the upper edge of the dotillid zone); high dotillid zone (1 $\mathrm{m}$ inside the high shore edge); mid-dotillid zone; low dotillid zone (1 $\mathrm{m}$ inside the low shore edge); and below the dotillid zone $(1 \mathrm{~m}$ outside the low shore edge). Samples were weighed and oven dried at $60^{\circ} \mathrm{C}$ to a constant weight. The total water content of the sediment was measured as the percentage weight loss of the sample. The dried samples were then sieved through a sieve stack ( 2 down to $0.064 \mathrm{~mm}$ mesh sizes) and each fraction weighed separately. The Gradistat program (Blott \& Pye 2001) was used to calculate the average sediment grain size (MDФ) and the sediment sorting (QDФ) from each sample. Surface sediment scrapes of $3 \mathrm{~mm}$ depth, representing the depth of sediment that Dotilla spp. processes when feeding (Luschi et al. 1997), were taken to analyse organic content. Each sample was oven dried at $60^{\circ} \mathrm{C}$ to a constant weight before being placed into a muffle furnace at $450^{\circ} \mathrm{C}$ for $6 \mathrm{~h}$. Samples were then reweighed, with the percentage weight loss representing the organic content of the sediment. Data were arcsine transformed, and nested ANOVA tests were used to see whether there were any significant differences in mean sediment total water content and mean sediment surface organic content between the different areas of the dotillid zone and between the 2 different beaches.

Principal component analysis (PCA) (Pearson 1901) was used to examine which environmental variables were most important in controlling the distribution of Dotilla intermedia on the beaches, with sediment data from Prapas Beach and Bang Ben collected in 2008 combined together. Four variables were examined: water content of the sediment, surface sediment organic content, MD $\Phi$ and $\mathrm{QD} \Phi$, with each variable taken from the above, high, middle, low and below areas of the dotillid zone on each transect.

\section{RESULTS}

\section{Boundaries of the dotillid zone}

The gradient of the beach calculated from each transect had a significant relationship with the height of the upper edge of the dotillid zone $(p<0.001)$ from Prapas Beach in November 2007 and April 2008, and from Bang Ben April 2008. The lower boundary of the dotillid zone was also significantly related to the beach gradient $(\mathrm{p}<$ 0.005). The $r^{2}$ values from the linear relationship show that the beach gradient is more closely related to the height of the high shore boundary of the dotillid zone than to that of the low shore boundary (Fig. 2).

\section{Sediment water and organic content}

The mean total water content of the sediment increased from above the high water boundary of the dotillid zone to the low water boundary (Fig. 3). Nested ANOVA showed that there was a significant difference between the water content of the 5 areas of the dotillid zone $\left(F_{4,5}=42.079, \mathrm{p}<0.001\right)$ and that there was no significant difference between Prapas Beach and Bang Ben within each beach area $\left(F_{5,30}=0.820\right.$, not significant). Holm-Sidak pairwise comparisons (Sidak 1967) showed that there was no significant difference be- 

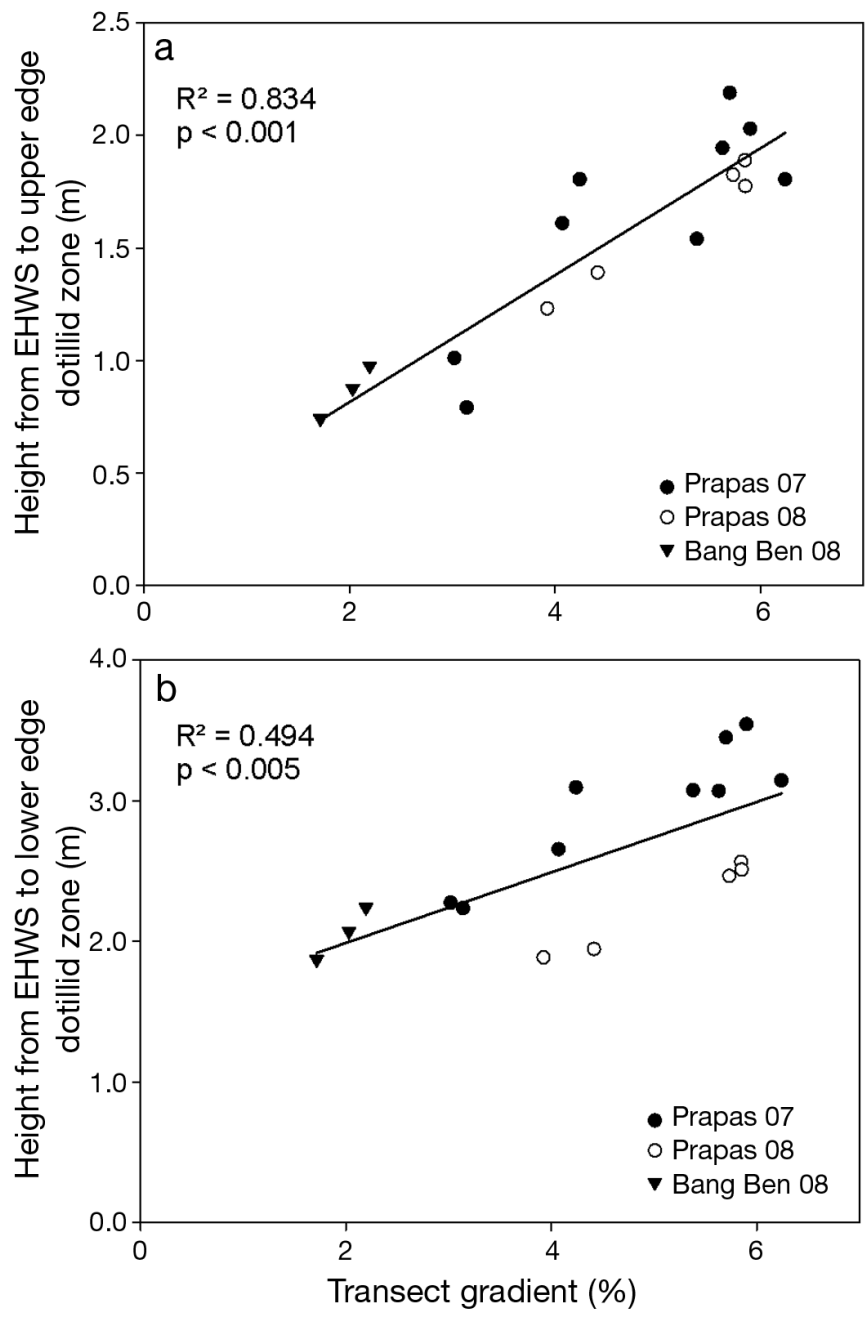

Fig. 2. Transect gradient plotted against the height from extreme high water spring (EHWS) of the boundaries of the dotillid zone. (a) Upper dotillid boundary. (b) Lower dotillid boundary. Height of upper edge dotillid zone $=0.2822 \times$ transect gradient +0.2501 . Height of lower edge dotillid zone $=$ $0.2508 \times$ transect gradient +1.4867

tween the mean water content from the low and below areas of the dotillid zone ( 22.5\%). Dotilla intermedia was only present in areas where total water content of the sediment was in excess of $15 \%$.

Mean total surface organic content of the sediment was also significantly different between the 5 areas of the dotillid zone $\left(F_{4,5}=37.578, \mathrm{p}<0.001\right)$, with no significant difference found between Prapas Beach and Bang Ben within each area of the dotillid zone $\left(F_{5,30}=\right.$ 1.545, not significant). However, when looking at the pairwise comparison, the only significant difference occurred between the above zone and below zone samples. The mean surface organic content increased from the high shore to the low shore, although the surface organic content was highly variable across the dotillid zone (Fig. 4).

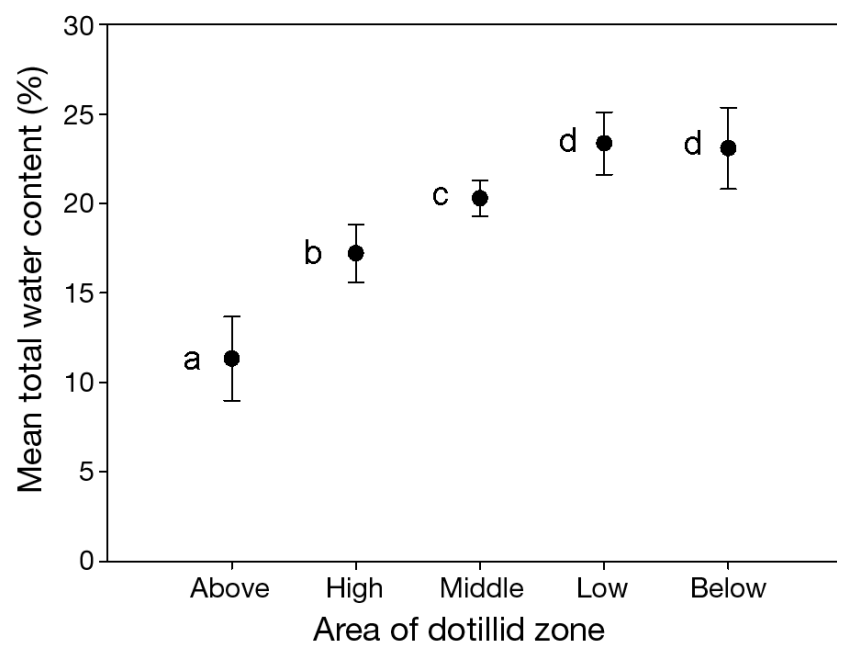

Fig. 3. Sediment mean total water content from different areas of the dotillid zone from Prapas Beach and Bang Ben 2008. Error bars represent $\pm 1 \mathrm{SD}, \mathrm{n}=8$. Different lower case letters denote statistically significant differences

\section{Principal component analysis}

The first 2 principal components (PC) were responsible for controlling the majority of the variation between the samples, with $\mathrm{PC} 1$ and $\mathrm{PC} 2$ representing $82.7 \%$ and $16.9 \%$ of the variation, respectively. PC1 was dominated by the influence of the total water content of the sediment, whilst the total organic content of the surface sediment was the most important vector in PC2. On a plot of PC1 against PC2 (Fig. 5) the samples from above the dotillid zone clustered together, and there was some grouping among the high and middle zone samples, although they were not as clearly defined as the above zone samples. The low and below

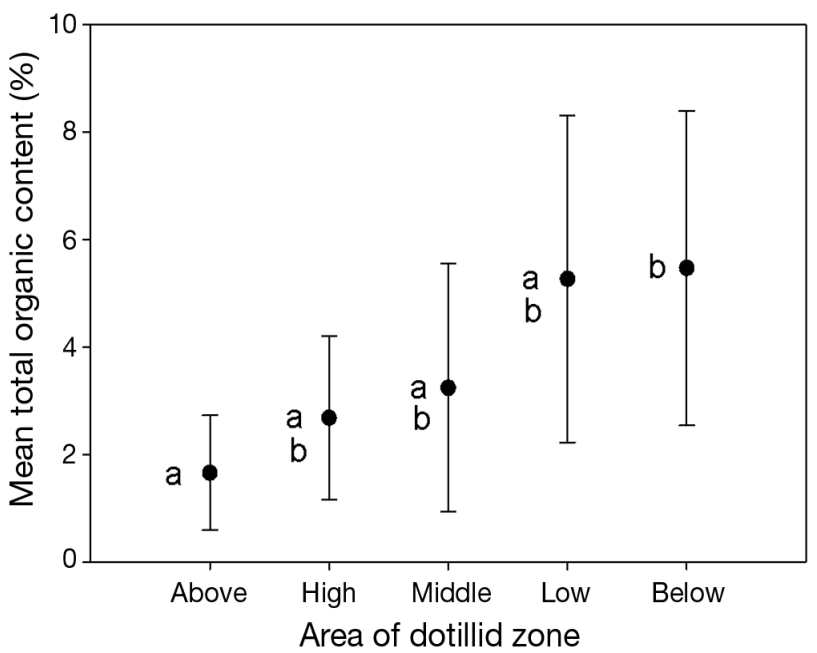

Fig. 4. Sediment mean total surface organic content from different areas of the dotillid zone from Prapas Beach and Bang Ben 2008. Error bars represent $\pm 1 \mathrm{SD}, \mathrm{n}=8$. Different lower case letters denote statistically significant differences 
zone samples appeared to be poorly separated from each other, suggesting that a variable not examined in the PCA was responsible for defining the lower limit of the dotillid zone.

The total water content of the sediment dominated the separation of the samples by their relative position within the dotillid zone (i.e. above, high, middle, low and below). There was a large amount of variation in the total surface organic content of the sediment, which differentiated between samples from within the same section of the dotillid zone, rather than between the different areas of the dotillid zone. Sediment grain size and sorting represented very little of the observed variation in the zonation of Dotilla intermedia.

\section{Size segregation}

Beach profiles (mean profile of all transects from each beach) for Prapas 2007, Prapas 2008 and Bang Ben 2008, along with crab CW size-frequency distributions for each area of the dotillid zone (upper, middle and low) are shown in Fig. 6. Kolmogorov-Smirnov tests showed significant differences $(p<0.001)$ between the size-frequency distributions of Dotilla intermedia from the upper, middle and low shore areas on each beach. The size distribution in the upper area was skewed towards crabs with a large CW, whilst the low shore area was characterised by a distribution skewed towards smaller CW. The middle area demonstrated a normal distribution in crab $\mathrm{CW}$ size-classes. The mean

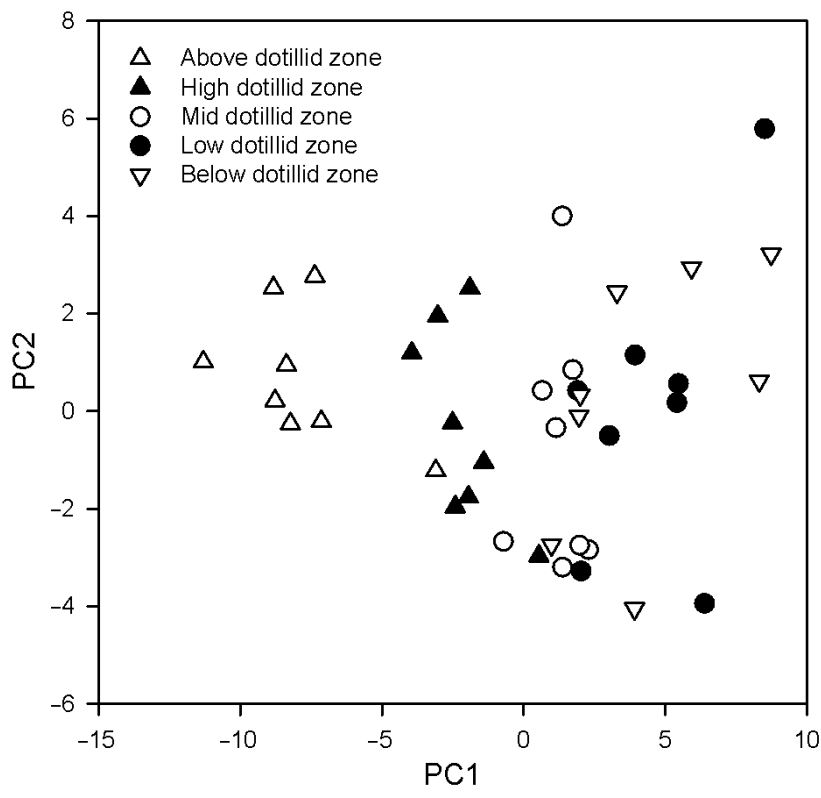

Fig. 5. Principal component 1 (PC1) versus PC2 from Prapas Beach and Bang Ben April 2008. The total sediment water content was the main component of $\mathrm{PC} 1$; the total surface sediment organic content was the main component of PC2 and median CW for each area of the dotillid zone decreased from the upper shore towards the low shore on each beach (Table 1).

There were also significant differences $(p<0.001)$ between the size-frequency distributions of the same shore areas from the different beaches. There was a higher percentage of larger size-classes at all shore heights in Prapas 2007 compared with Prapas 2008, whilst Bang Ben was occupied by even larger crabs.

\section{Population density, crab size and feeding}

The density of Dotilla intermedia within each $0.25 \mathrm{~m}^{2}$ quadrat had a close relationship with the mean size of the feeding area of the crabs. As density increased, the size of the mean feeding area decreased (Fig. 7). The upper limit of the mean feeding area followed an inverse power curve that designated a maximum size to the feeding area at a given density of $D$. intermedia (maximum mean feeding area $\left[\mathrm{cm}^{2}\right]=425 \times$ density crabs $^{-0.695}$ ). Thus, at a density of 100 individuals (ind.) $0.25 \mathrm{~m}^{-2}$ each crab would have a mean maximum-sized feeding area of $17.3 \mathrm{~cm}^{2}$, whilst 50 ind. $0.25 \mathrm{~m}^{-2}$ would have a maximum mean feeding area of $28 \mathrm{~cm}^{2}$ each. The values falling under this curve may have resulted from starting the sampling before the crabs had had enough time after tidal emersion to feed sufficiently to reach the maximum extent. There was a significant relationship between the log mean CW and the log mean feeding area within a quadrat (Pearson correlation coefficient $=0.713, \mathrm{p}<0.0001$ ). The size of the mean feeding area increased as the mean $\mathrm{CW}$ in a quadrat increased (Fig. 8).

\section{Nearest neighbour analysis}

At low densities, the R-value showed that crabs had a regular distribution in each quadrat. As density increased, the R-value decreased, with distribution becoming more random. By an abundance of around 10 ind. $0.25 \mathrm{~m}^{-2}$ the R-values had stabilised at around 1.3 to 1.5 , representing a random distribution with a slight trend towards regular spacing within each quadrat, as opposed to aggregation. These trends were common from both beaches in 2007 and 2008 (Fig. 9).

\section{DISCUSSION}

\section{Dotillid zonation}

The heights of the upper and lower boundaries of the dotillid zone were closely related to the gradient of 

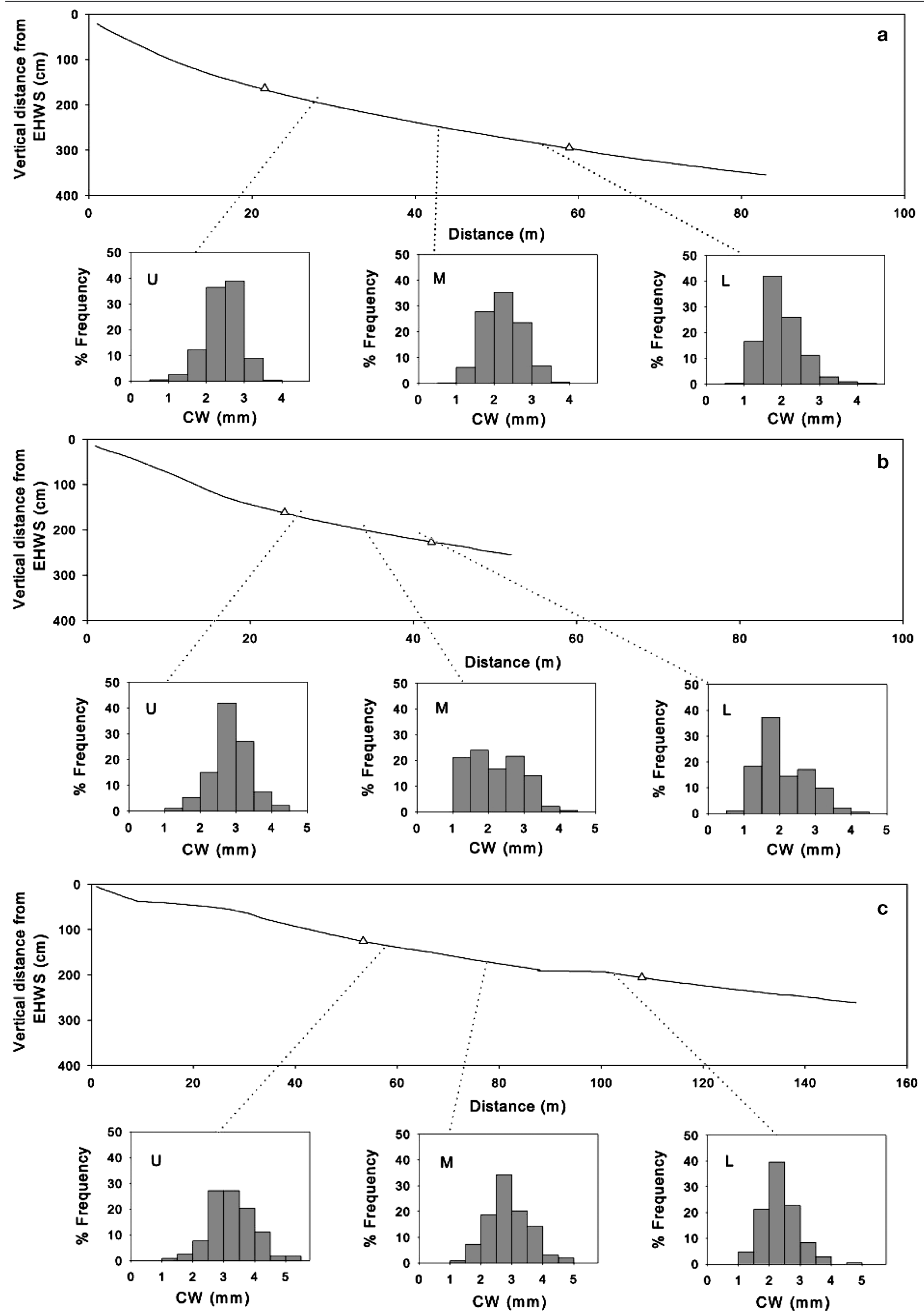
Fig. 6. Dotilla intermedia. Carapace width (CW) size-class frequency at different beach zones. (a) Prapas Beach 2007; (b) Prapas Beach 2008; (c) Bang Ben 2008. Beach profiles represent the mean profile of all transects for that beach. Triangles denote the boundaries of the dotillid zone on each beach. Histograms show CW distribution in 3 areas of the dotillid zone: upper (U), middle (M) and lower (L)

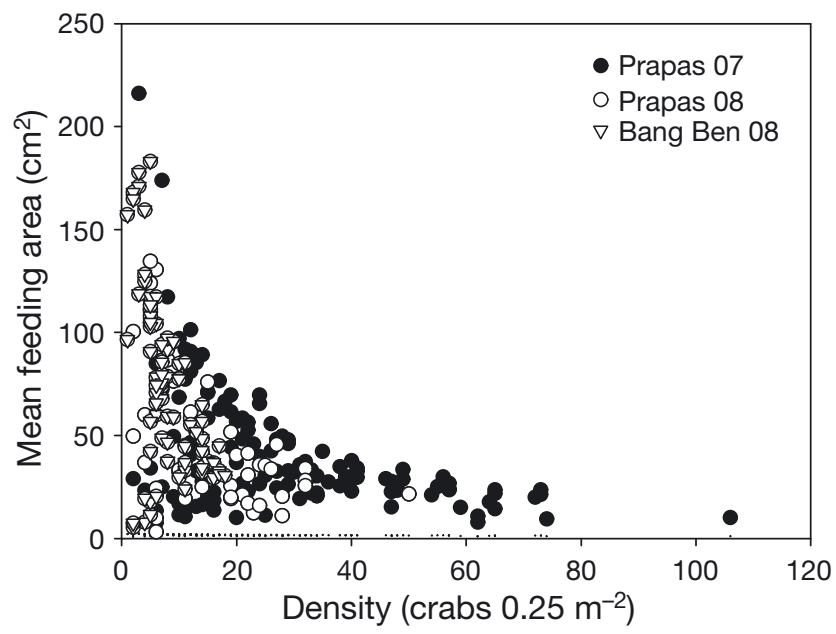

Fig. 7. Dotilla intermedia. Density of crabs plotted against mean feeding area within a quadrat $\left(0.25 \mathrm{~m}^{2}\right)$

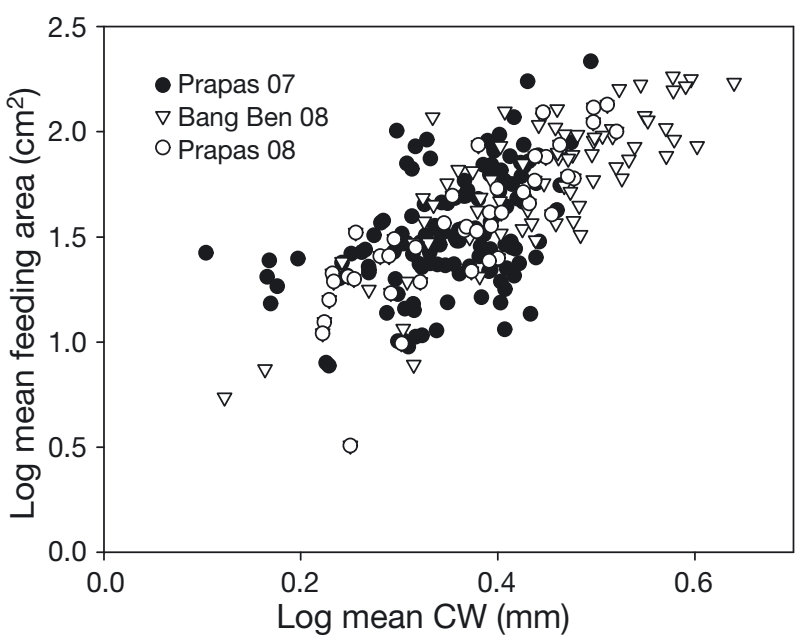

Fig. 8. Dotilla intermedia. Log mean crab carapace width (CW) plotted against log mean feeding area within a quadrat $\left(0.25 \mathrm{~m}^{2}\right)$

Table 1. Dotilla intermedia. Mean and median carapace width (mm) for the upper, middle and lower areas of the dotillid zone on Prapas Beach 2007 and 2008 and Bang Ben 2008

\begin{tabular}{|lcccccc|}
\hline \multirow{2}{*}{$\begin{array}{l}\text { Area of } \\
\text { dotillid zone }\end{array}$} & \multicolumn{2}{c}{$\begin{array}{c}\text { Prapas Beach 2007 } \\
\text { Mean }\end{array}$} & Median & \multicolumn{2}{c}{$\begin{array}{c}\text { Prapas Beach 2008 } \\
\text { Mean }\end{array}$} & \multicolumn{2}{c|}{ Mang Ben 2008 } \\
Mpper & 2.43 & 2.46 & 2.83 & 2.85 & 3.25 & 3.23 \\
Middle & 2.23 & 2.19 & 2.21 & 2.17 & 2.89 & 2.84 \\
Lower & 1.98 & 1.90 & 2.06 & 1.85 & 2.34 & 2.31 \\
\hline
\end{tabular}

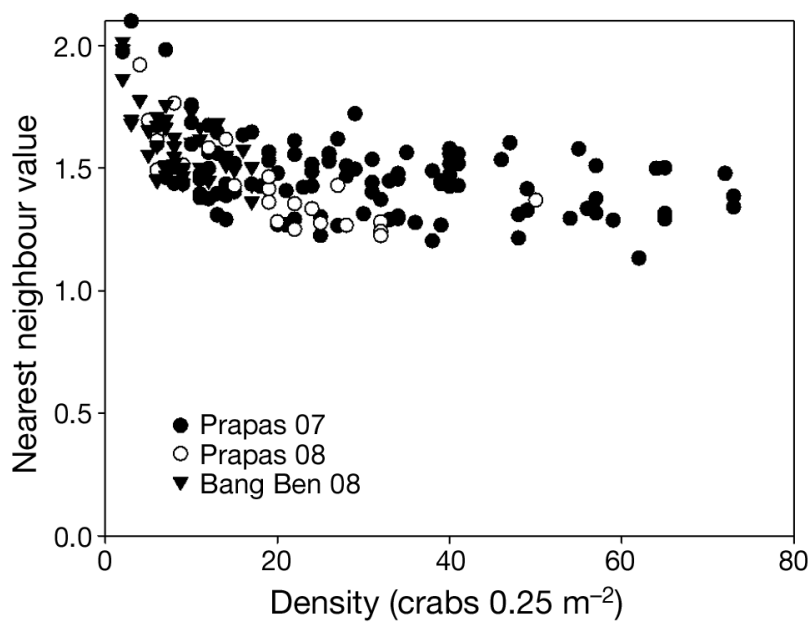

Fig. 9. Dotilla intermedia. Density of crabs per quadrat (no. crabs $0.25 \mathrm{~m}^{-2}$ ) plotted against R-value

the beach and its associated physical factors. The upper boundary of the dotillid zone was defined by the total water content of the sediment. The absolute height of the upper limit of the dotillid zone is not constant and will change over time. Sediment accumulation or removal will alter the beach gradient, which will change the water table height and, in turn, affect the water content of the sediment at a given point on the beach.

Dotilla intermedia were only found in sediments with a water content of $15 \%$ or higher. One of the distinguishing features of dotillid crabs is the presence of a band of setae on the 4th abdominal segment that function in water uptake. The abdomen can be lowered, pressing the setae into the sand allowing the uptake of interstitial water (Hartnoll 1973). The presence of such an adaptation indicates an evolutionary importance of water to dotillid crabs. Both Scopimera spp. and Dotilla spp. possess membranous disks, known as 'tympana' or gas windows, on the meral segments of their legs. Tympana are respiratory surfaces that function in aerial gas exchange (Maitland 1986). The tympana in Scopimera are thinner than in Dotilla, allowing Dotilla to have relatively greater respiratory efficiency, but at the cost of poorer water and ion retention (Matsumasa et al. 2001). Dotilla may be restricted to 
sediments with greater water content to offset the increased rate of water loss through the tympana, whereas Scopimera are better adapted to survive higher up the beach where the sediment water content is lower. The increased respiratory efficiency of Dotilla, combined with the presence of water uptake setae to balance water loss, may allow members of this genus to spend more time on the surface without returning to their burrows compared with those of Scopimera. This would maximise the time available between emersion and immersion by the tide, thus permitting Dotilla to occupy areas lower down the beach than Scopimera. Examining a single species like $D$. intermedia highlights the importance of species physiology on community structure, which may be lost when examining sandy beach ecology only at the community level.

Mean surface organic content decreased higher up the shore, although there were no significant differences between the values found in the areas occupied by Dotilla intermedia and those measured in the area above the dotillid zone. Despite low surface organic content, the high shore area above the dotillid zone was still inhabited by Scopimera sp., which feeds in an identical manner to dotillid crabs (Zimmer-Faust 1987). If the organic content of the sediment was sufficient to support Scopimera sp., then it would be unlikely that $D$. intermedia could not survive in this area, supporting the hypothesis that surface organic content was not a factor controlling the upper limit to the dotillid distribution.

The upper limit to the dotillid zone could potentially be defined by competition with Scopimera. However, no direct interactions were observed between the 2 species during the investigation (C. J. Allen pers. obs.). The very low densities at which both Scopimera sp. and Dotilla intermedia occurred on the high shore made competition for space or resources unlikely. Nevertheless, further work involving exclusion pens and transplanting dotillid crabs into the Scopimera zone and vice versa would clarify the role competition plays, if any, on delimiting the upper boundary of the dotillid zone.

The lower boundary of the dotillid zone was governed by the tide. The activities that Dotilla intermedia can perform are limited by the time between each successive immersion by the tide. The area on the shore occupied by $D$. intermedia needs to have sufficient time available between tides for individuals to feed (Hartnoll 1973, Fishelson 1983) in addition to engaging in other behaviours, such as burrow maintenance, mating and territorial displays (Gherardi et al. 1999); $D$. intermedia must therefore live a certain distance from the low water mark. The lower edge of the dotillid zone will shift according to the spring neap tidal cycle. By looking at the vertical height from the lower edge of the dotillid zone to the low water mark and examining the tide tables for the region, we determined that the lower limit of the dotillid zone is exposed for approximately 4 to $5 \mathrm{~h}$ between successive immersions.

Bradshaw \& Scoffin (1999) concluded that the main factor governing the distribution of Dotilla myctiroides in Tang Khen Bay, Phuket, was the duration of the daytime exposure (i.e. the amount of time the crabs were emersed between tides). The crabs occupied the tops of sand ripples in the bay, with pools of water present on either side of each ripple. This potentially kept the water content of the sediment sufficiently high so it did not become a limiting factor in the species distribution, leaving the period of tidal emersion as the driving factor.

Inhabiting an area too close to the low water mark imposes other physical environmental restrictions for Dotilla intermedia. The development of suction, s, (i.e. negative pore water pressure relative to atmospheric pressure) is an essential threshold condition for the creation of burrows by Scopimera globosa, with burrowing performance depending strongly on the state of $s$ in association with the groundwater level (Sassa \& Watabe 2008). In low water areas, the value of $s$ is not favourable for the construction of the semi-permanent cylindrical burrows found higher on the shore, thus resulting in the formation of 'igloo' style burrows instead. A number of Dotilla species have been reported to construct 2 different forms of burrow: simple vertical cylindrical tubes, and 'igloo'. An igloo is formed by the crab rotating in the sand beneath the surface and forming a wall of sand pellets around and over itself and is built in semi-fluid unstable sand (Takeda et al. 1996). A higher percentage of igloos were seen in the low shore than higher on the beach (C. J. Allen pers. obs.).

Sediment grain size and sorting was not responsible for controlling where Dotilla intermedia were found on the beach. Sediment particle size was not a critical factor in defining the zonation of D. myctiroides from Porto Novo in India, with individuals found in sediment with the silt-clay fraction ranging from 0.3 to $30 \%$ (McIntyre 1968). However, it is likely that sediment grain size would be the ultimate limiting factor in dictating which beaches would be suitable for $D$. intermedia to inhabit. In estuarine areas of the Laem Son National Park where sediment grain size was smaller, $D$. intermedia was replaced by D. myctiroides. Sediment grains need to be of a certain size to be sifted through the mouthparts of Dotilla spp., and different species favour different sized particles depending on the nature of their spoon-tipped setae (Vogel 1984). The division of habitats by sediment grain size has also been demonstrated in Uca (e.g. Lim 2004). However, sediment particles that are too big cannot be fed upon, and beaches need to have sediment types suitable for the construction of burrows (Ansell 1988). To define 
the limits of sediment particle sizes inhabited by $D$. intermedia further investigation covering more beaches with a wider range of grain sizes would be required.

Surveys were made of other beaches in the region and around Phuket. Those that had coarse sand were not occupied by any dotillid crabs, although those with fine sand were inhabited by Dotilla myctiroides (C. J. Allen \& G. L. J. Paterson pers. obs.). These observations would match the predictions of current hypotheses concerning how changing beach morphodynamics affect species distributions. As beaches move from dissipative in character (i.e. fine sand, flat slopes, low substrate penetrability and high water content) to reflective (i.e. coarse sand, short swash periods, steep slopes, high substrate penetrability, low organic matter and low sediment water content) species are excluded due to the harsher swash climate (swash exclusion hypothesis; McArdle \& McLachlan 1991, 1992) and the coarser sands making the environment more inhospitable (habitat harshness hypothesis; Defeo et al. 2001, 2003).

\section{Dotillid density patterns}

The highest observed densities of Dotilla intermedia from the present study were from Prapas Beach in 2007 and ranged from 12 to 424 ind. $\mathrm{m}^{-2}$, with an average of 102 ind. $\mathrm{m}^{-2}$. These density counts are lower than those reported for other species, with $D$. fenestrata having density counts of 48 to 564 ind. $\mathrm{m}^{-2}$ (Hartnoll 1973) and D. myctiroides 178 to 501 ind. $\mathrm{m}^{-2}$ (Hails \& Yaziz 1982).

The size of the feeding area around each burrow was closely related to crab size and the density of the population. McIntyre (1968) observed that the length of the longest feeding track from the burrow in Dotilla myctiroides was crucially important in determining the density of the population. As crab size increased the size of the feeding area also increased, meaning that large crabs lived at lower densities than did small crabs. This would lead to intraspecific competition for space within the dotillid zone. The random to regular distribution indicated by the nearest neighbour analysis suggests that individuals were fitting their feeding areas around one another, probably mediated by territorial interactions between individuals (see Schöne 1968 for descriptions of agonistic displays in Dotilla).

Dotillid crabs feed in roughly circular zones. Assuming their feeding territories do not overlap as crab density increases, it would be expected that the nearest neighbour values would begin to demonstrate a trend towards a more regular distribution, as the circular feeding zones are arranged around one another to maximise the available space. However, this was not shown by the data. The range of crab sizes that were found at all densities may mask this trend, with a vari- ety of different-sized circular feeding areas increasing the number of possible arrangements in a given area, leading to a variation in nearest neighbour distances and resulting in a more random than regular spatial distribution.

Nutrient replenishment of the sediment varies between tides following the deposition of organic material. This creates patchiness in organic richness both temporally and spatially. Variation in the organic content of the sediment did not appear to have any effect on the distribution of Dotilla on the shore. The nearest neighbour data indicated that crabs tended towards a random distribution across the shore rather than being aggregated together as would be expected if they were grouping in the same area to exploit a food patch with high organic content.

\section{Size segregation}

There was a difference in the pattern of distribution between large and small crabs within the dotillid zone. The area close to the low water was dominated by smaller crabs, with larger crabs occurring mainly from the mid-shore upwards. This was more pronounced on Bang Ben than on Prapas Beach. Size segregation may possibly act as an evolutionary process to partition space and avoid intraspecific competition for food and space, with each population component having a differential capacity to select a desirable microhabitat (Defeo \& McLachlan 2005). The habitat favourability hypothesis (Caddy \& Defeo 2003) suggests that under optimal conditions, the centre of a species range may be occupied by larger and more dominant intraspecific competitors for food and space, whereas small individuals (recruits) may be displaced towards suboptimal conditions on one or both extremes of the species distribution range. The optimal area for the large dotillid crabs appears to be the upper area of the dotillid zone, with smaller crabs displaced towards to the low shore. The differences in the size frequency distributions observed between Prapas Beach in 2007 and 2008 result from some individuals growing over time, leading to the higher percentages of the larger size-classes in 2008. The flatter beach profile of Bang Ben led to a wider dotillid zone, providing more space for crabs to feed and attain larger body sizes than on Prapas Beach.

The low water area may be suboptimal for larger crabs as the short exposure time would result in less time to feed. Assuming crabs feed at the same rate regardless of size, larger crabs would need to feed in a larger area and require more time. This may not be a problem for smaller crabs, which may be able to gather enough energy from feeding for the 4 to $5 \mathrm{~h}$ before low shore immersion. 
The geophysical conditions of the low shore may make the construction and maintenance of semi-permanent vertical burrows more difficult. The vertical burrows of Dotilla myctiroides are used in their mating behaviour, with male crabs capturing females and pushing them into their burrows (Tweedie 1950). The inability to construct vertical burrows in the low shore may prevent mating from occurring there, thus restricting mature crabs to areas higher up the beach. For example, Uca tangeri prefers the higher tidal zone (Klaassen \& Ens 1993). The increased exposure time allows for the construction of deeper burrows, which also provide better predation protection.

Hartnoll (1973) suggested that the adult Dotilla fenestrata preferred lower stations where particle size was smaller, with associated higher organic and water content. Very little variation in sediment grain size was observed in the present study, perhaps eliminating this effect in structuring the distribution of the larger adult crabs on the beach. Although the surface organic content did increase towards the low water, it was highly variable across the whole dotillid zone.

The presence of small crabs in all areas of the beach may be due to juveniles settling into any patches available on the shore. Larger crabs avoid the lower shore, which may result in high numbers of small crabs settling there. Small crabs were observed across the entire dotillid zone on Prapas, but there tended to be fewer small crabs in the high shore region. The survival rate of the small crabs on different parts of the beach is unknown, although it is hypothesised to be lower farther up the beach, due to the crabs' reduced ability to cope with the longer levels of exposure in this region (Pellegrino 1984). This has also been observed in other species of Dotilla (Hartnoll 1973, Dray \& Paula 1998, Flores et al. 2005).

In a wider context, this study provides support for Dahl's (1952) and Salvat's (1964) generalised schemes of sandy shore zonation. Dahl (1952) divided the shore into 3 zones based on the distribution of characteristic crustacean species, whilst Salvat (1964) split the shore into 4 regions based on changes in sand moisture content. The boundaries of some of Dahl's (1952) and Salvat's (1964) zones roughly coincide, showing a correspondence between physical and biological zones on sandy beaches, as demonstrated by the large influence sediment water content has on the distribution of Dotilla intermedia.

Although moisture zones do generally coincide with faunal zones, faunal zones are dynamic and vary temporally. The physical boundary of a species distribution depends on the swash and moisture zones on the shore and not on absolute tide level. Therefore, it is better to define such flexible zones on the basis of centres of distribution of characteristic taxa rather than on sharp boundaries defined by Salvat's (1964) sand moisture levels (McLachlan \& Jaramillo 1995). The change in the area occupied by Dotilla intermedia on Prapas Beach between 2007 and 2008 demonstrates this variability, and why the use of characteristic species is a more robust method of defining beach zones than is sand moisture content.

\section{CONCLUSIONS}

The boundaries of the zone inhabited by dotillid crabs were related to the physical factors imposed by the beach gradient. The high shore limit is defined by the total water content of the sediment, with Dotilla intermedia absent from sediment with less than 15\% total water content. The low shore boundary of the zone is set by the temporal constraints of the tidal cycle, with crabs requiring a minimum amount of time ( 4 to $5 \mathrm{~h}$ ) between tidal immersions to feed. Within the dotillid zone, there are patterns of distribution associated with the size of the crabs; larger crabs live higher up the beach than do smaller crabs. The observed distribution of $D$. intermedia is consistent with the predictions of several non-contradictory hypotheses concerning patterns observed on sandy beaches. Size segregation across the beach follows the habitat favourability hypothesis, whilst the absence of any populations on more reflective beaches matches the predictions of the habitat harshness hypothesis. This study demonstrates that the study of a single key species can identify the physical processes that drive zonation patterns on sandy shores and elucidate what underlying factors influence community structure in sandy beach ecosystems.

Acknowledgements. The authors thank the staff of the Kasetsart University Ranong Coastal Resources Research Station, Kampuan, Thailand, for their hospitality and use of the facilities. Thanks are also due to members of the Tsunami Impact in Thailand Project for logistic support and discussions, particularly Nor Jub and Ball and Dr. B. Foster-Smith for discussions and advice on using MapInfo. We also thank the 3 anonymous reviewers for their comments on the manuscript. This study was supported by a NERC CASE studentship (NER/S/A/2006/ 14217 ) to C.J.A. which is gratefully acknowledged.

\section{LITERATURE CITED}

Alcock A (1900) Materials for a carcinological fauna of India. No. 6. The Brachyura Catometopa, or Grapsoidea. J Asiatic Soc Bengal 69(3):279-456

Ansell DA (1988) Migration or shelter? Behavioural options for deposit feeding crabs on tropical sandy shores. In: Chelazzi G, Vannini M (eds) Behavioural adaptations for life. Plenum Press, New York, NY, p 15-26

> Blott SJ, Pye K (2001) Gradistat: a grain size distribution and statistics package for the analysis of unconsolidated sedi- 
ments. Earth Surf Process Landf 26:1237-1248

Bradshaw C, Scoffin TP (1999) Factors limiting the distribution and activity patterns of the soldier crab Dotilla myctiroides in Phuket, South Thailand. Mar Biol 135:83-87

Caddy JF, Defeo O (2003) Enhancing or restoring the productivity of natural populations of shellfish and other marine invertebrate resources. FAO Fish Tech Pap 448. FAO, Rome

Clark PJ, Evans FC (1954) Distance to nearest neighbour as a measure of spatial relationships in populations. Ecology 35:445-453

Dahl E (1952) Some aspects of the ecology and zonation of the fauna on sandy beaches. Oikos 4:1-27

$>$ Defeo O, McLachlan A (2005) Patterns, processes and regulatory mechanisms in sandy beach macrofauna: a multiscale analysis. Mar Ecol Prog Ser 295:1-20

Defeo O, Gómez J, Lercari D (2001) Testing the swash exclusion hypothesis in sandy beach populations: the mole crab Emertia brasiliensis in Uruguay. Mar Ecol Prog Ser 212: $159-170$

Defeo O, Lercari D, Gómez J (2003) The role of morphodynamics in structuring sandy beach populations and communities: What should be expected? J Coast Res 35(Spec Issue):352-362

> Dray T, Paula J (1998) Ecological aspects of populations of the crab Dotilla fenestrata (Hilgendorf, 1869) (Brachyura: Ocypodidae), in the tidal flats of Inhaca Island (Mozambique). J Nat Hist 32:1525-1534

Fishelson L (1983) Population ecology and biology of Dotilla sulcata (Crustacea, Ocypodidae) typical for sandy beaches of the Red Sea. In: McLachlan A, Erasmus T (eds) Sandy beaches as ecosystems. Dr W Junk, The Hague, p 643-654

Flores AAV, Abrantes KG, Paula J (2005) Estimating abundance and spatial distribution patterns of the bubble crab Dotilla fenestrata (Crustacea: Brachyura). Austral Ecol 30: $14-23$

> Gherardi F, Russo S, Anyona D (1999) Burrow-orientated activity in the ocypodid crab, Dotilla fenestrata, living in a mangrove swamp. J Mar Biol Assoc UK 79:281-293

Hails AJ, Yaziz S (1982) Abundance, breeding and growth of the ocypodid crab Dotilla myctiroides (Milne-Edwards) on a West Malaysian beach. Estuar Coast Shelf Sci 15: $229-239$

Hartnoll RG (1973) Factors affecting the distribution and behaviour of the crab Dotilla fenestrata on East African shores. Estuar Coast Mar Sci 1:137-152

> Jaramillo E, McLachlan A, Dugan J (1995) Total sample area and estimates of species richness in exposed sandy beaches. Mar Ecol Prog Ser 119:311-314

Klaassen M, Ens BJ (1993) Habitat selection and energetics of the fiddler crab (Uca tangeri). Neth J Sea Res 31:495-502

Lee SL, Lim SSL (2004) Do diameters of burrows and food pellets provide estimates of the size structure of a population of Dotilla myctiroides at the sand-flats of Ao Tung Khen, Phuket? Phuket Mar Biol Cent Res Bull 65:55-60

Lim SSL (2004) A comparative study of some mouthparts of Uca annulipes ( $\mathrm{H}$. Milne Edwards, 1937) and U. vocans (Linnaeus, 1758) (Brachyura; Ocypodidae) in relation to their habitats. Crustaceana 77:1245-1251

Luschi P, Del Seppia C, Crosio E (1997) Orientation during short-range feeding in the crab Dotilla wichmanni. J Comp Physiol A 181:461-468

MacNae W, Kalk M (1962) The fauna and flora of sand flats of Inhaca Island, Mozambique. J Anim Ecol 31:93-128

Maitland DP (1986) Crabs that breathe air with their legs-Scopimera and Dotilla. Nature 319:493-495

Matsumasa M, Kikuchi S, Takeda S, Poovachiranon S, Yong
HS, Murai M (2001) Blood osmoregulation and ultrastructure of the gas windows ('Tympana') of intertidal ocypodid crabs: Dotilla vs. Scopimera. Benthos Res 56:47-55

> McArdle S, McLachlan A (1991) Dynamics of the swash zone and effluent line on sandy beaches. Mar Ecol Prog Ser 76: 91-99

McArdle S, McLachlan A (1992) Sandy beach ecology: swash features relevant to the macrofauna. J Coast Res 8:398-407

McIntyre AD (1968) The meiofauna and macrofauna of some tropical beaches. J Zool 156:377-392

McLachlan A (1990) Dissipative beaches and macrofauna communities on exposed intertidal sands. J Coast Res 6: $57-71$

McLachlan A, Dorvlo A (2005) Global patterns in sandy beach macrobenthic communities. J Coast Res 21:674-687

McLachlan A, Jaramillo E (1995) Zonation on sandy beaches. Oceanogr Mar Biol Annu Rev 33:305-335

McLachlan A, Woodridge T, Dye AH (1981) The ecology of sandy beaches in southern Africa. S Afr J Zool 16:219-231

McLachlan A, Jaramillo E, Donn TE, Wessels F (1993) Sand beach macrofauna communities: a geographical comparison. J Coast Res 15:27-38

Noy-Meir I (1979) Structure and function of desert ecosystems. Isr J Bot 28:1-19

Ólafsson E, Ndaro SGM (1997) Impact of the mangrove crabs Uca annulipes and Dotilla fenestrata on meiobenthos. Mar Ecol Prog Ser 158:225-231

Pearson K (1901) On lines and planes of closest fit to systems of points in space. Philos Mag 2:559-572

- Pellegrino CR (1984) The role of desiccation pressures and surface area/volume relationships on seasonal zonation and size distribution of four tropical intertidal decapod Crustacea from New Zealand: implications for adaptation to land. Crustaceana 47:251-268

Salvat B (1964) Les conditions hydrodynamiques interstitielles des sediments meubles intertidaux et la repartition verticale de la fauna endogee. Cah Rech Acad Sci Paris 259:1576-1579

- Sassa S, Watabe Y (2008) Threshold, optimum and critical geoenvironmental conditions for burrowing activity of sand bubbler crab, Scopimera globosa. Mar Ecol Prog Ser 354:191-199

Schöne H (1968) Agonistic and sexual display in aquatic and semi-terrestrial Brachyuran crabs. Am Zool 8:641-654

Sidak Z (1967) Rectangular confidence regions for the means of multivariate normal distributions. J Am Stat Assoc 62: 626-633

Sokal RR, Rohlf F (1995) Biometry: the principles and practice of statistics in biological research, 3rd edn. W. H. Freeman, New York, NY

Takeda S, Matsumasa M, Yong HS, Murai M (1996) 'Igloo' construction by the ocypodid crab, Dotilla myctiroides (Milne-Edwards) (Crustacea; Brachyura): the role of an air chamber when burrowing in a saturated sandy substratum. J Exp Mar Biol Ecol 198:237-247

Tweedie MWF (1950) Notes on Grapsoid crabs from the Raffles Museum. Bull Raffles Mus 23:310-324

Vogel F (1984) Comparative and functional morphology of the spoon-tipped setae on the second maxillipeds in Dotilla Stimpson, 1858 (Decapoda, Brachyura, Ocypodidae). Crustaceana 47:225-234

Warner GF (1977) The biology of crabs. Paul Elek (Science Books), London

Zimmer-Faust RK (1987) Substrate selection and use by a deposit-feeding crab. Ecology 68:955-970

Zwarts L (1985) The winter exploitation of fiddler crabs Uca tangeri by waders in Guinea-Bissau. Ardea 73:3-12 